\title{
On Identity Statements: In Defense of a Sui Generis View
}

\begin{abstract}
Tristan Haze
University of Sydney

DOI: $10.2478 /$ disp-2016-0016

BIBLID [0873-626X (2016) 43; pp. 269-293]

Abstract

This paper is about the meaning and function of identity statements involving proper names. There are two prominent views on this topic, according to which identity statements ascribe a relation: the objectview, on which identity statements ascribe a relation borne by all objects to themselves, and the name-view, on which an identity statement ' $a$ is $b$ ' says that the names ' $a$ ' and ' $b$ ' codesignate. The object- and name-views may seem to exhaust the field. I make a case for treating identity statements as sui generis instead of attempting to explain them by means of the idea that they ascribe a relation. My contention is that once we do this, no analysis is required.
\end{abstract}

\section{Keywords}

Identity statements, informative identities, numerical identity, names, Frege.

\section{Orientation}

Frege began his (1893), and with it the modern discussion of identity statements, thus: "Equality ${ }^{1}$ gives rise to challenging questions which are not altogether easy to answer. Is it a relation? A relation between objects, or between names or signs of objects?" In the arguments which follow, Frege seems to tacitly assume it must be a relation,

${ }^{1}$ Frege uses the same term, 'equality', both for mathematical equality and identity. He uses '=' for 'is' when writing identity statements, presumably to avoid using 'is' both predicatively and for identity. This might seem like trading one ambiguity in for another. Of course, on Frege's view, a mathematical equality is a kind of identity statement. Since I do not wish to address or prejudge this question, when quoting Frege, I convert '=' back to 'is'. I also put quote marks around schematic sentences.

Disputatio, Vol. VIII, No. 43, November 2016

Received: 18/01/2016 Revised: 12/04/2016 Accepted: 07/07/2016 
exploring the two alternatives which then arise. ${ }^{2}$

I call these the object-ascription view and the name-ascription view - for short, the object-view and the name-view. The name-view is naturally coupled with the claim that identity statements are grammatically misleading (for not explicitly mentioning names). In Frege's discussion, these views are intended to cover statements featuring referring terms other than proper names; he considers examples involving definite descriptions such as 'the intersection of $a$ and $b$ ' (Frege 1893: 26). Here I concentrate on the proper name case - that is, I treat the two relation-ascription views as concerning only that case. (By 'proper name' I mean things like 'Frege', 'Santa Claus' and 'Australia' — I exclude definite descriptions and referring words like 'this' and 'that'. No doubt there are unclear or borderline cases, but I will not worry about that here.)

The object- and name-views may seem to exhaust the field; we have (with a few exceptions, more on which below) carried on under Frege's tacit assumption that identity statements ascribe a relation.

The view I want to develop in this paper can be seen as a denial of this assumption. But this is not a thesis I wish to hold rigidly; it need not be harmful to call identity a relation. For example, Quine (1960: 116) writes that '[w]hat makes identity a relation, and '=' a relative term, is that ' $=$ ' goes between distinct occurrences of singular terms". I would not want to quarrel with this usage. My central point is that a relation-ascription view of identity statements leads to confusion because there is a fundamental disanalogy between identity statements and other two-termed statements, which modern philosophy — in calling them all relational, and bringing the same logical and semantic ideas to bear on them - has obscured. This will be seen to parallel the more recognized disanalogy between existence statements and other one-termed statements.

So, without getting caught up in arguments about how the word 'relation' ought to be used, here I wish to argue against the relationascription views construed as accounts of the meaning of identity

\footnotetext{
${ }^{2}$ Frege is commonly interpreted as settling on a sophisticated object-ascription view (cf. Dummett 1981: 544, Salmon 1986: $51-54$ and Weiner 1999: 91 92). Dejnozka (1981) and Thau and Caplan (2001) challenge this view. I do not consider this exegetical question here.
} 
statements (section 2), and then make clear the fundamental disanalogy (section 3). Once we get used to the idea that identity statements are of a quite distinctive kind, they will no longer appear problematic. Despite not fitting the relation-ascription model, they have a legitimate use, can be true and false, and can give information.

I am not the first to express dissatisfaction with both relationascription views. My most notable predecessors are P.F. Strawson, David Wiggins (in an early paper) and Thomas V. Morris. ${ }^{3}$

Strawson's (1974) contribution is low on argument against the relational views, and the diagrammatic models he employs are merely described, not depicted, which makes his points less striking than they might have been. These models parallel ones I employ in section 3. Strawson uses dots for objects, where I use boxes. This makes it easier for me to develop the models a little further, and to make their results stateable as well as visible. ${ }^{4}$

Wiggins's (1965), in contrast to Strawson's discussion, is brimming with arguments against the relational views, but his proposed alternative is vague, unattractively similar to the name-view, and was not taken up again by Wiggins in any later work. Also, I think there are additional strong lines of attack available which Wiggins does not take or mention in the negative part of his article.

Morris (1984) can be seen as elaborating on the work of Strawson. He sees his task not as finding better objections to the dominant view (the object-view), but rather to show that there is a decent alternative. His proposed alternative, however, is presented as a kind of analysis. It has faced published objections which have apparently gone unanswered (cf. Noonan 1986, Newman 1992). What I have to say, though in some respects similar, will be much less loaded (I think) with unclear or objectionable claims and aspects of presentation.

\footnotetext{
${ }^{3}$ What I say in section 3 also has points of contact with François Recanati's work on mental files, e.g. Recanati 2012. Compared to what I am doing here, Recanati's work is more about the theory of reference, and about constructive theorizing for general purposes, than about resolving the peculiar philosophical difficulties which arise when we think of identity statements as relational. This seems to be more of a difference of interest and emphasis than a difference of opinion, however.

${ }^{4}$ I developed these models independently, being struck in the process by their power and naturalness. It was gratifying to discover Strawson's pre-emption.
} 
This will be seen when I come to address possible objections to my approach, in section 4 .

In general, there are two major pitfalls for this kind of approach which no one has yet succeeded in avoiding: the great unclarity of what it means to deny the object-view, and the urge to provide an alternative analysis of identity statements. I avoid the first pitfall, since I do not insist that the object-view is false — only that it does not explicate the meaning of identity statements. I avoid the second pitfall by maintaining that no analysis of identity statements is required, and that we should question and resist the urge to provide one. It may seem like we are left with a gap in our accounts if we turn away from the relation-ascription views. I think this is an illusion. Giving identity statements full recognition as a logical form in their own right makes their meaning transparent, and we no longer need any "theory of identity". We just move from a cruder to a more nuanced view of an important aspect of the logic of our language. I think those who desire a theory or analysis of identity statements have fallen under the spell, so common in philosophy, of trying to force a kind of statement into an unsuitable mould. My method is to study identity statements on their own terms - to see how they work and that they work, without trying to assimilate them to other types of statements. The urge to say something more must be checked by the fact that nothing more needs saying.

This is not as radical or novel as it perhaps sounds. Since Kant, for instance, it has become a commonplace in philosophy that 'exists' is not a predicate, existence not a property, and that existence statements do not ascribe a property to objects. ${ }^{5}$ To suppose otherwise engenders confusion, and by carrying on in this way we do better. So here we have a successful case of a non-ascriptional, sui generis view of a kind of statement. I think we should let identity statements enjoy the same kind of understanding.

\footnotetext{
${ }^{5}$ This has been reinforced by our interpretations of classical logic, in which all names must refer, thereby rendering questions of particular existence external to the system.
} 


\section{Against the relational views}

Let us begin with the object-view, since it is the more obvious view, as well as being contemporary philosophical orthodoxy. It says that every object bears a relation to itself, identity, that this relation holds only between objects and themselves, and that what identity statements do is ascribe this relation.

The central objection to this is given by Frege in his landmark discussion. He begins with the observation that identity statements of the form ' $a$ is $a$ ' are trivial and a priori, whereas statements of the form ' $a$ is $b$ ', I quote, "often contain very valuable extensions of our knowledge and cannot always be established a priori" (Frege 1893: 25). "Now," Frege says,

if we were to regard equality as a relation between that which the names ' $a$ ' and ' $b$ ' designate, it would seem that ' $a$ is $b$ ' could not differ from ' $a$ is $a$ ' (i.e. provided ' $a$ is $b$ ' is true). A relation would thereby be expressed of a thing to itself, and indeed one in which each thing stands to itself but to no other thing. (Frege 1893: 25-26).

This is the famous problem of informative identity statements. The raising of this problem constitutes Frege's initial argument against the object-view. I think it is a good argument. Many obviously do not take it this way, however, since the object-view is nowadays often treated by philosophers as though it is obviously right. ${ }^{6}$ What has happened might become clearer if we see what Frege goes on to say. But first, let me repeat that I think this simple argument gives us every reason to reject the object-view as an account of the meaning of identity statements.

Frege, for now going with the thrust of the above argument, immediately raises the alternative of the name-view:

What is intended to be said by ' $a$ is $b$ ' seems to be that the signs or

${ }^{6}$ An influential statement of this viewpoint was made by Lewis (1986: 192193): "Identity is utterly simple and unproblematic. Everything is identical to itself; nothing is ever identical to anything else except itself. There is never any problem about what makes something identical to itself; nothing can ever fail to be." (Noonan and Curtis (2014: preface) call this viewpoint 'increasingly popular'.) For me this passage calls to mind Wittgenstein's (1953: §351) remark that "[i]t is much easier to bury a problem than to solve it". 
names ' $a$ ' and ' $b$ ' designate the same thing, so that those signs themselves would be under discussion; a relation between them would be asserted. (Frege 1893: 26)

But then he gives some kind of argument to show that this will not work either. Here it is in full:

But this relation would hold between the names or signs only in so far as they named or designated. It would be mediated by the connexion of each of the two signs with the same designated thing. But this is arbitrary. Nobody can be forbidden to use any arbitrarily producible event or object as a sign for something. In that case the sentence ' $a$ is $b$ ' would no longer refer to the subject matter, but only to its mode of designation; we would express no proper knowledge by its means. But in many cases this is just what we want to do. (Frege 1893: 26)

This argument seems to constitute Frege's reason for abandoning the name-view (which he in fact held, in Frege 1879: §8). The first two sentences seem quite clear, and correct. But then: "But this is arbitrary." (Frege 1893: 26). That is, "[t]he connexion of each of the two signs with the same designated thing" is arbitrary.

Certainly, you will have two connections between name and object, and both will of course be arbitrary (in the sense that all such connections are). But why does Frege conclude that we could therefore express no "proper knowledge" this way? Can't you make one arbitrary connection with ' $a$ ', another with ' $b$ ' and then learn - attain proper knowledge — that these connections are to the same object? Frege seems to have overlooked the fact that once you establish two connections, though they may be arbitrary, it is no longer arbitrary, no longer a matter of decision, whether they are to the same object or not. That is already determined, and you may not know which way.

Frege's claim that if the name-ascription view were right, "the sentence ' $a$ is $b$ ' would no longer refer to the subject matter, but only to its mode of designation", while suggestive, is also without force. For what is the subject matter, here? The object — or objects, if the identity statement is false — designated by ' $a$ ' and ' $b$ ', or ' $a$ ' and ' $b$ ' themselves? The only way Frege's point has a chance of being right is if we assume the former, for the names ' $a$ ' and ' $b$ ' themselves are plainly referred to on the name-ascription view. But to assume the 
former - that the subject matter is the object(s), not the name - is to beg the question against the name-view!

We have now seen Frege offer one good objection to the objectview and one bad objection to the name-view. Nevertheless, the main thing we see in the wake of his arguments is a widespread adoption of the object-view. One reason for this, I think, is that the argument against the name-view, even though it is a bad argument, gets us thinking along lines such that we correctly intuit that the view is wrong. (This will become clearer later in this section when I offer what I take to be good arguments against that view.) With no alternative in sight, we are pushed back towards the object-view and forced to look for some way for it to overcome the problem of informative identity statements.

The first thing to note is that whatever strategy the proponent of the object-view employs, they cannot explain the potential informativeness of ' $a$ is $b$ '-statements, in contrast to their ' $a$ is $a$ ' counterparts, by appealing to any difference in what relation is ascribed to which objects. Of course, on this view, false identity statements will be held to ascribe identity to a different pair of objects from any ' $a$ is $a$ ' statement, but all true identity statements of the form ' $a$ is $b$ ' will be the same as their ' $a$ is $a$ ' and ' $b$ is $b$ ' counterparts with respect to the relation and object involved. Thus 'Hesperus is Phosphorus' ascribes the same relation to the same object (and itself, if you like) as 'Hesperus is Hesperus'. The object-view's defender must account for the difference in informativeness in some further way - their relational account of what identity statements express does not do the job by itself.

This is attempted in a number of different ways. One big division here is between accounts which deny that there is a semantic difference, a difference in what is said, between ' $a$ is $a$ ' and a corresponding informative ' $a$ is $b$ ', and accounts which accept that there is a semantic difference. The former must locate the difference in something extra-semantic. Leading accounts of this kind are those of Salmon $(1986,1989,1991)$ and Soames $(1987,1989,1998,2002)$. Their chief motivation for attempting to account for the difference extra-semantically is the desire to uphold a Millian theory of names, on which there is nothing more to the meaning of a name than its 
referent. ${ }^{7}$ The classic example of an account which allows that there is a semantic difference between ' $a$ is $a$ ' and ' $a$ is $b$ ' is of course that of Frege (1893) as standardly interpreted: he introduces sense as a part of semantics over and above reference, allowing ' $a$ ' and ' $b$ ', and in turn ' $a$ is $a$ ' and ' $a$ is $b$ ', to differ semantically. A major contemporary descendant of this approach, building on mid-century developments of Frege's idea such as Carnap 1947 and Church 1951, is that of Chalmers $(2002,2004)$. These semantic approaches have in common that they locate the semantic difference between ' $a$ is $a$ ' and ' $a$ is $b$ ' in a semantic difference between ' $a$ ' and ' $b$ '. Recently, there has appeared a semantic approach on which a semantic difference between the statements is admitted but not traced to a semantic difference between ' $a$ ' and ' $b$ ': Fine's (2007) semantic relationism.

I am not contending that any of these approaches to explaining the difference between ' $a$ is $a$ ' and ' $a$ is $b$ ' are idle or gratuitous. As I see it, this is work which has to be done whether or not the object-view is to be upheld — adopting the sui generis view of identity statements I am arguing for in this paper does not absolve one from having to do it. ${ }^{8}$ My contention is that, with all these approaches, once the difference is explained, the main claim of the object-view

\footnotetext{
7 These extra-semantic accounts have arguably unpalatable consequences. 'Hesperus is Hesperus' is bound to say something trivial (putting aside any implication that Hesperus exists, at least). Therefore if 'Hesperus is Phosphorus' says the same thing, we are pushed toward concluding that what it says is trivial, yet expressed in a way that makes it informative. Either that, or that 'Hesperus is Hesperus' manages to express something substantial in such a way as to make it trivial. (Note that this is not analogous to the way a Babylonian may find 'Hesperus is visible in the evening' informative, while not 'Phosphorus is visible in the evening': these two sentences are both capable of being informative, and if they do express the same proposition in some sense, then that proposition is certainly substantial.)

${ }^{8}$ I favour an approach which steers between Millianism and Fregeanism; I count the role a name plays in a system of language as part of its meaning. This nicely combines the difference-making power of Fregean senses (and their neo-Fregean descendants) with invulnerability to anti-descriptivist arguments. (The individuation of roles is a flexible affair; recognizing this allows us to solve Kripke's (1979) puzzle about belief.) This is not the place to develop this view, which is in no way required by the sui generis view of identity statements I am advancing in this paper.
} 
— that identity statements ascribe a relation which holds between everything and itself and in no other case — starts to look pretty useless as a theory. Rather than explaining the meaning and function of identity statements, it just becomes, at best, "something you can say". And that is my position. If the proponent of the object-view is still to have something worth saying, they need to tell some story on which identity statements crucially ascribe the identity relation, but also "do other stuff". I suggest that in any reasonable story, the "other stuff" would do most of the work, and the object-view's core claim would be an idle cog.

So much against the object-view as an account of the meaning of identity statements. We have now reached a dialectical point at which the name-view may seem attractive. It has been out of favour largely for the wrong reasons, and could seem like a neglected, promising alternative. We shall now consider four objections to it. The first objection, while natural and conspicuous in the literature, turns out to be weak. The other three are stronger.

\section{The Circularity Objection}

The name-view says that ' $a$ is $b$ ' means 'The names " $a$ " and " $b$ " designate the same object', but the phrase 'same object' here just re-invokes the concept of identity. Therefore the analysis does not explicate the meaning of ' $a$ is $b$ '.

This objection can be found in Russell (1903: Appendix A, 'Meaning and indication') and Kneale and Kneale (1962: 494-495). An elaborated version is given in Wiggins 1965. In this version, 'The names " $a$ " and " $b$ " designate the same object' gets explicated as 'The designatum of " $a$ " is the designatum of " $b$ ", and this in turn is subjected to analysis according to the name-view, giving us a regress. But this elaboration is (a) unclear about why "The names " $a$ " and " $b$ " designate the same object' has to, or ought to be, reformulated, and (b) inapplicable for us, because the reformulation involves definite descriptions, and we are considering the name-view narrowly construed as concerning only the proper name case, thus blocking the regress.

A more fundamental problem with this sort of objection is that there is another way of explicating "The names " $a$ " and " $b$ " designate the same object', a way which does not seem to re-invoke the concept 
of identity. We can explicate this statement as meaning 'There is an object $x$ such that " $a$ " designates $x$ and " $b$ " designates $x$..

Thus this objection to the name-view, while natural, turns out to be relatively weak. Fortunately, stronger objections are available.

\section{The Logical Objection}

Adoption of the name-view pushes us toward a revision of logical theory, if the latter is to retain its power. I think this revision plainly seems like it should be avoidable. That a revision seems necessary given the name-view has been appreciated by authors discussing Frege's views and Wittgenstein's early work, ${ }^{10}$ but the point remains absent from many discussions which deal directly with the nameview. Here is a simple way to see it:

Imagine a yellow piece of paper with two names, ' $a$ ' and ' $b$ '. The name ' $a$ ' itself has a name, ' $j$ ', and likewise the name ' $b$ ' is called ' $k$ '. With arrows representing reference relations, this situation can be represented with the following diagram:

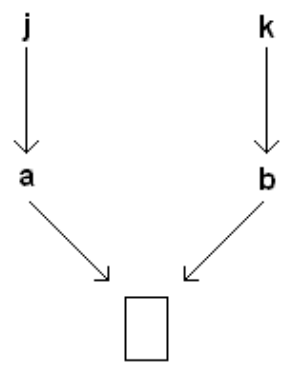

If someone knows that $a$ (the piece of paper) is yellow, and that $a$ is $b$, they are in a position to infer that $b$ is yellow. Now, in ordinary

${ }^{9}$ This solution to the circularity objection is adopted in Wehmeier (2012: 796). The question of whether statements like 'There is an object $x$ such that " $a$ " designates $x$ and " $b$ " designates $x$ ' tacitly invoke identity themselves is explored thoroughly in another connection by Humberstone and Townsend (1994). They conclude that the claim that they do "can be resisted" (Humberstone and Townsend 1994: 243).

${ }^{10}$ E.g. White (1978). 
logical theory, this argument is straightforwardly valid. In simple notation:

Ya

$\mathrm{a}=\mathrm{b}$

$\therefore \mathrm{Yb}$

This is a very direct inference, an exemplar of the inference rule of identity elimination. Crucial to its application is the fact that the name in the first premise re-appears in the second.

But if we accept the name-view of identity statements, this no longer seems to be the case. Remember, given the name-view, the natural thing to say is that ' $a$ is $b$ ' has a misleading surface structure; what it really says is that two particular names codesignate. In that case, the second premise should be reformulated, employing a relational term for codesignation (instead of ' $=$ '), and names of the names ' $a$ ' and ' $b$ '. We have already given ' $a$ ' and ' $b$ ' names, namely ' $j$ ' and ' $k$ ', and we will use ' $C$ ' for the co-designation relation. Thus reformulated to accord with the name-view, our argument becomes:

Ya

Cjk

$\therefore \mathrm{Yb}$

Now, how is the conclusion to follow?

The first statement says that some object is yellow, and the second says that two names codesignate. For the conclusion to follow, additional premises stating what the names designate are required, as well as a new, more complicated, logical principle to replace identity elimination. Another route, which would avoid the first step at least, might be to introduce a quotational apparatus, so instead of ' $j$ ' and ' $k$ ' as names of ' $a$ ' and ' $b$ ', we would have the syntactically complex “'a”' and "“b”, or something similar.

In addition to seeming to complicate these logical inferences, adoption of the name-view also widens the terms of reference of statements and arguments, apparently unnecessarily. In ordinary logic, in a domain containing only pieces of paper, our inference to the yellowness of $b$ goes through. For the inference to go through 
with the name-view of identity statements, the domain needs to contain names as well as pieces of paper. Furthermore, on a natural way of extending the name-view to cover cases where the identity sign is flanked by variables, names become involved even for many statements which do not - even to the holder of the name-view, I would think - seem to have anything to do with names. For example, to say that $a$ and only $a$ is yellow (that $a$ is the yellow thing). In standard logic:

$\mathrm{Y} a \wedge(\forall x)(\mathrm{Y} x \supset x=a)$

$a$ is yellow and everything yellow is $a$.

This would have to be replaced by something like:

$\mathrm{Y} a \wedge(\forall x)\left[(\exists y)\left(x \mathrm{D} y \wedge \mathrm{Y}_{y}\right) \supset \mathrm{xD} a\right]$

$a$ is yellow and everything which designates something yellow designates $a$.

Another response to this may be simply to strip logic of ' $=$ ' and everything that comes with it. But if logic loses its power to encode information like the above, it no longer provides any account of inferences like ' $a$ is the only yellow thing, therefore $a$ is yellow'. But these seem as logical and subject-neutral as any. ${ }^{11}$

\section{The Language-Independence Objection}

This objection is bound up with an issue touched on in the previous one - that we apparently use identity statements to say things which have nothing to do with names. Statements of codesignation and genuine identity statements can come apart, so the former cannot be a correct analysis of the latter. I will show this in two ways:

${ }^{11}$ Relevant here is Wehmeier 2012. Wehmeier, dissatisfied with the objectview, offers a strategy for avoiding ' $=$ ' in logic but retaining the expressive power that comes with it by using Wittgensteinian/exclusive quantifiers, and couples this with an endorsement of the name-view of ' $a$ is $b$ ' statements. From a formal point of view, his quantifier strategy is interesting and its possibility instructive, but the point remains: this seems like a needless departure from standard logical theory. As I will argue later in the present paper (section 4), we can reject the object-view while leaving '=' in logic largely untouched. 
one involving the distant past, and one involving considerations of what can be imagined.

First, consider the situation in our solar system, 5 million years ago. The names 'Hesperus' and 'Phosphorus' were not then being used to refer to Venus. So, 5 million years ago, 'Hesperus' and 'Phosphorus' did not codesignate. But it seems wrong to say that Hesperus was not Phosphorus then.

It may be thought that this objection can be avoided by saying that identity/codesignation statements are in a certain sense tenseless, or always present-tense, or something along those lines. I do not for my part see how that could plausibly be maintained, but for this reason perhaps the following approach is stronger:

Consider these imperatives:

(1) Imagine that 'George W. Bush' codesignates with 'Mick Jagger'.

(2) Imagine that George W. Bush is Mick Jagger.

You can comply with (1) without complying with (2): you could imagine that the former U.S. president has always been called something else, say 'John Bush', and that Mick Jagger has long been known by two names, 'Mick Jagger' and 'George W. Bush'. Or you could imagine that there is some third person with two names one shared with the president, one with the musician. If any of these imaginings were actually the case, 'George W. Bush is Mick Jagger' might be true. But at least one of those names would then have a different referent from what we actually suppose it to have. We in the real world cannot correctly describe these imaginings as of situations in which George W. Bush is Mick Jagger.

Note that considerations analogous to these hold against a nameview about existence statements. 'George W. Bush exists' does not mean 'The name "George W. Bush" designates': you can imagine George W. Bush having a different name. Also, you can imagine that 'George W. Bush' designates someone else and George W. Bush himself never existed. (More generally: Things exist. This truism does not amount to the claim that names designate.) And of course, a name-view about ordinary predications also faces such problems: the truth of the sentence 'John is tall' may show us that the name 'John' refers to someone tall, but the sentence says no such thing: you can 
imagine John being tall but being called something else.

(Soames (2014) gives a similar objection to the name-view, but in terms of believing what is expressed by an identity sentence despite being ignorant of the language it is written in. He writes: "identity sentences are not metalinguistic (...) since one who has no knowledge of English can believe the thought expressed by (19a) without believing the thought expressed by (19b)" (Soames 2014: 94). ((19a) is an identity statement involving two definite descriptions and (19b) is a metalinguistic analysis of it.) This particular objection is stronger for the case of definite descriptions, which we are excluding from consideration, than it is for the proper name case, since it may be maintained that proper names are not really part of English.)

\section{The Mystification Objection}

What exactly does the name-view state? Does it say that a statement of the form ' $a$ is $b$ ':

- means the same as " a" codesignates with " $b$ ”"

- has no clear meaning

- means nothing, or

- will be false for ascribing a non-genuine relation?

These all seem like holdable views, but all are alike, I want to say, in making a mystery (at best) out of current linguistic practice involving identity statements.

Take the first brand, the meaning-equivalence claim. The problem then is: how could it have come about that the ' $a$ is $b$ ' form is used in our language to mean that a codesignation relation obtains between two names? Ordinarily, we use names to say something about the objects they refer to, not the names themselves. And this is no simple use-mention confusion or autonymous use of names: we cannot, of course, say that we really mean ' $a$ " is " $b$ ". If the nameview as meaning-equivalence is right, it states a linguistic fact which would appear to defy, and yet call for, explanation. And the puzzle cannot be confined to the basic form of identity statements. Here are two further puzzles:

'Clark Kent has a secret, namely that he is Superman.' What does this say? Clark Kent's secret does not seem to be about two names 
codesignating — and if it is, then how does that sentence manage to say so?!

Lois Lane may truly say 'Clark Kent is Superman; he told me directly', if he said to her - in his Clark Kent guise — 'I am Superman'. Now we seem to be in the position of having to interpret this too as meaning that 'Clark Kent' codesignates with 'Superman'. (And remember that Clark Kent, in his office clothes, could give information to someone else with the sentence 'I am Superman', and this person need not know that there is any name other than 'Superman' involved. They may just conclude that Superman sometimes wears office attire and glasses.)

How about the second version, on which ' $a$ is $b$ '-statements lack a clear meaning? If this version is to be distinct from the previous, on which ' $a$ is $b$ '-statements have a "hidden" meaning, it would seem to imply that these statements cannot say anything clearly, and should be replaced by codesignation statements. But if that is the case, we have some explaining to do. Namely, of how people manage in so many cases to feel sure that they are clearly conveying information, very often with palpable practical upshot, when they are not. The same consideration holds for the remaining two views, on which instances of ' $a$ is $b$ ' are all meaningless and all false respectively.

\section{The fundamental disanalogy}

To exhibit the fundamental disanalogy between identity statements and relational statements (or between identity statements and other relational statements, should you prefer), we shall employ the following non-lexical means of representation: Boxes are to represent objects, dots to represent instantiation of either properties or places in relations ascribable to the objects, lines to label the properties or indicate the relations, and arrows (when needed) to show the direction of the relations. Thus, corresponding to 'John is happy' is this graph:

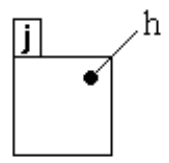


'John loves Mary':

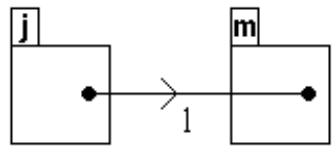

'John told Kang about Mary':

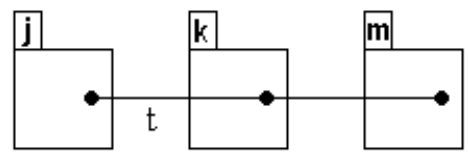

'John introduced himself to Mary':

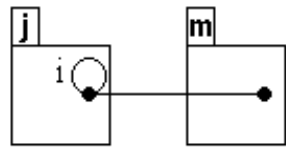

(The letters here can be thought of as abbreviations for 'John', 'happy' etc., or autonomous signs which stand for individuals, properties and relations. For relations of more than two places, we adopt the convention of placing the relation's label next to the first connecting line, in the process rendering the arrow superfluous. For reflexive connections, as in the last example, a loop - a curved connecting line - is drawn.)

These graphs could be used to make assertions, like their corresponding sentences. In this use, let us call them 'graph-propositions'. They could also be used to model a set of beliefs, or a base of knowledge, about some domain. In this use, we shall call them 'beliefmaps'. Representations very much like belief-maps are used in many areas of activity - detective work, software development, genealogy, business management, and magazine reportage about romantic interconnections between celebrities, to name a few.

We will only need to consider very simple uses of this form of representation, but note that there are further possibilities than those illustrated above. For example, we could use this graph-proposition 
for 'John loves someone':

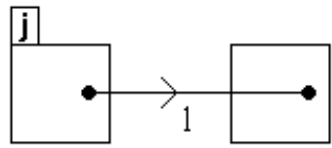

And this one for 'John gave something to Mary':

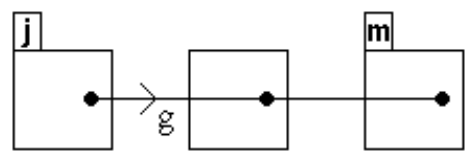

(Or we might prefer to omit the unlabelled boxes, just leaving a dot.)

Graph-propositions like these can be seen as a partial specifications of, or constraints on, belief-maps. This is obviously true for the last two examples, but no less true for the others. Accordingly, we observe the following principle:

Incorporation principle: If a graph-proposition is accepted, and a belief-map modified accordingly, the graph-proposition will be incorporated in the result. ${ }^{12}$

We can imagine graph-propositions being used in tandem with belief-maps. Each person might maintain a belief-map about some area - and if someone asserts a graph-proposition, and they come to accept it, they then modify their belief-map to incorporate it, often in the process making many alterations to the map. And this is how it is in word-language. When someone asserts a proposition, and you come to believe it, you will typically, in the process, also change your attitude to countless other propositions.

${ }^{12}$ It would also be possible to make a negative use of graph-propositions, which could be signified by a special symbol, akin to a sentential operator. In this case a non-incorporation principle would be natural. Note in this connection that I am not claiming that the incorporation principle as stated above would hold for all possible extensions of technique of graph-propositions. The point is that the principle is a natural one for the sorts of examples we are considering. 
In asserting a sentence, one as it were says: 'Whatever you do, assent to this.' This is particularly clear with propositions we accept with some difficulty. You cannot just accept a proposition by itself and leave everything as it is; you must accommodate it. This accommodation corresponds to the full incorporation of a graph-proposition. The asserter of a graph-proposition is in effect saying: 'Whatever you do, make part of your belief-map look like this.'

Now we are in a position to consider the following question: What might be a suitable graph-propositional correlate to an identity statement, for example 'Clark Kent is Superman'? Well, what would the dominant view (the object-view) suggest? Presumably, since identity statements ascribe a relation on this view, a connecting line will be involved. Modelling 'Clark Kent is Superman' on 'John loves Mary', we get:

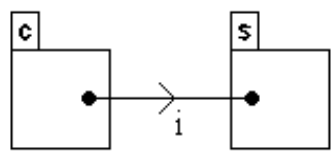

Or, building the symmetry of identity statements into the graph-proposition:

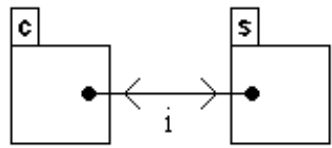

But these are not suitable correlates, for they would not satisfy the incorporation principle. We can see this by asking: What kind of changes might one make to a belief-map upon accepting an identity statement, given in words? Suppose Lois Lane, prior to accepting the identity statement, believed that Clark Kent worked in an office, and that a separate individual, Superman, fought crime. So her beliefmap would incorporate:
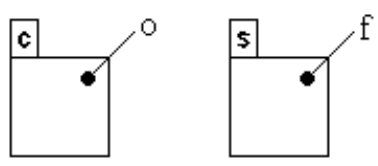
Upon accepting that Clark Kent is Superman, we can imagine Lois Lane accommodating this by, among other things, supposing that this individual — Clark Kent, Superman — changes clothes in phone-booths when no one is looking. Her resulting belief-map would not incorporate the suggested correlates. Rather, she would change it to look like this:

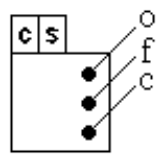

where 'c' stands for something like 'changes clothes in phone-booths'. Thus if we still want to represent Clark Kent's being Superman using a relation line, without flouting the incorporation principle, we should have to have:

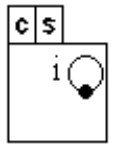

But this loop could have no significance, for everything is identical to itself. We could put it in every box. Since this device could serve no purpose, let us forbid it. Omitting it, we get:

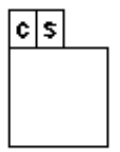

Or simply:

\section{cs $s$}

And thus we have arrived at a suitable graph-propositional correlate to 'Clark Kent is Superman', satisfying the incorporation principle.

(Note the similarity with 'Clark Kent is Superman', if we consider 'is' as a kind of connector and separator here — not so different from its use in 'Clark Kent is smart' — rather than standing for a 
relation. ${ }^{13}$ )

The fundamental disanalogy between identity statements and relational statements can now be stated in this way: an identity statement's most suitable graph-propositional correlate is of a completely different form from that of a relational statement.

Another interesting feature of the technique of graph-propositions is that there is no natural correlate to trivial identity statements, or at least none of the same form as the correlate of a potentially informative identity statement. I.e., a belief-map would not contain something like:

Or at least this could serve no purpose. We are therefore free to forbid it, as we did with "identity loops" above. Now, the above, as a graph-proposition, does not satisfy the incorporation principle. All we have left to opt for as a correlate to ' $a$ is $a$ ' is:

回

And this is not of the same form as a correlate to a potentially informative identity statement. Thus no "problem of informative identity" arises for graph-propositions.

This shows us that there is no problem for word-language either, seen clearly. We are led astray by the formal similarity between identity statements and relational statements in our language, and by the highly various and complicated use we make of these forms. We do, for instance, sometimes utter repetitive 'is' sentences. We might say 'John is... John' to indicate that he is a quite singular person, or perhaps suggesting that one can't say much about John without being impolite, as we might do equally well with: 'What can I say?'. These uses go with characteristic gestures and tones of voice. Also, we have

${ }^{13}$ This conception is expressed in a footnote in Wertheimer (1998: $180 \mathrm{fn}$. 3): "The 'is' of both identity and predication is a semantically empty functional expression ordering pairs of terms to form sentences." Note that it is no objection to this to point out that ' $a$ is $b$ ' is equivalent to ' $a$ is identical to $b$ ', ' $a$ is the same object as $b$ ', and numerous other expressions. After all, ' $a$ is red' is equivalent to 'a possesses the property of being red' as well. 
the dictum that "every thing is what it is, and not another thing" (Butler 1726: preface), which somehow manages to be a useful reminder in philosophy. It should be clear, however, that none of these uses plays anything like the role that 'Clark Kent is Superman' might play for Lois Lane. It is that kind of use which is explicated with the technique of graph-propositions.

Graph-propositions make it clear as day why ' $a$ is $b$ '-statements can embody empirical information in that way, while ' $a$ is $a$ '-statements never find any such use. We can, if we want, say that 'Clark Kent is Superman' and 'Clark Kent is Clark Kent' both ascribe the relation of identity, but that does not explicate their meaning. They are different sentences with different uses.

\section{Possible objections answered}

Objection 1: Standard logic treats identity as a relation. What are you going to do about that?

Reply: Axioms and rules of inference involving ' $=$ ' can remain as they are, but we should understand this symbol as being fundamentally different from (other) relational terms. To some extent, we already do: '=' is distinguished by being treated as a logical constant. To take the separation further, the grammars of logical languages could treat ' $=$ ' as the sole member of its own category of expression, but this amendment would not change which formulae get recognized as grammatical.

The main thing which needs rethinking is the standard modeltheoretic semantics for ' $=$ '. Roughly speaking, instead of saying that a certain relation holds between all objects and themselves only, and that an ordered pair $<_{o_{1}}, o_{2}>$ satisfies ' $x=y$ ' iff $o_{1}$ bears this relation to $o_{2}$, we could leave out any talk of this relation, and just say an ordered pair $<_{o_{1}}, o_{2}>$ satisfies ' $x=y$ ' iff $o_{1}$ is $o_{2}$, i.e., iff the ordered pair is repetitive. This appears no less rigorous than the common procedure (which to my mind has, by comparison, the aspect of a logical trick).

Objection 2: You give no account of what happens when someone accepts an identity statement and then changes their mind. ${ }^{14}$

${ }^{14}$ This objection is made in Noonan 1986 to the Strawson-Morris approach. 
Reply: That is true, but no such account was needed for our task - to break the grip of the way of thinking which made a relational view of identity statements look inevitable. And what has been said here hardly blocks the way to understanding mind-changing; if Lois Lane accepted but then changed her mind about Clark Kent being Superman, she would adjust her belief-map to be like it was before, but perhaps with added information about having been misled, certain misleading appearances, etc.

That we can do such things is certainly a remarkable fact of nature. I, of course, have no special duty to explain it. But it may be helpful in this connection to note: if two names ' $a$ ' and ' $b$ ' are used interchangeably by all competent speakers, the denial of ' $a$ is b' would have no clear meaning — we could not begin to accommodate it. Identity statements, and denials thereof, have their characteristic uses in quite particular circumstances.

Objection 3: What you say about graph-propositional correlates may be well and good, but you have made no contribution to answering the question of what identity statements say. ${ }^{15}$

Reply: If knowing what a statement says consists in understanding its meaning and use, then graph-propositions can contribute to this. But they are no part of any project to say, definitively, what identity statements say. I think this sort of philosophical task, in an instance such as this, is stranger than is commonly perceived.

Let us stop to reflect on the practice of asking and answering the question of what something says, apart from any specialized philosophical instances. Consider these cases:

- Asking what is said by a sentence of a foreign language.

- Hearing of an inscription on the inside of an urn - asking what it says.

- Explaining, precisely, the conventional meaning of 'The average man has 1.4 children'.

- Rendering, e.g., 'Insouciance was ubiquitous' in more common language.

${ }^{15}$ An objection to Morris like this one (but not in terms of graph-propositions) appears in Newman 1992, except Newman also suggests that perhaps Morris thinks that identity statements say nothing. Obviously, that is not my view. 
- Replacing an unnecessarily long and involved sentence with a better-constructed one.

- Summing up what is said in an article, book, speech etc.

'Clark Kent is Superman', however, appears to be about the plainest, simplest expression in English of what it says. I would suggest that any philosophical puzzlement about such statements is not to be alleviated by a theory of what identity statements say, but by recognizing that they are logically and semantically sui generis. ('Saying what identity statements say' should be compared with 'saying what subject-predicate statements say' — not, for example, 'saying what velocity statements say'.) $)^{16}$

Tristan Haze

University of Sydney tristanhaze@gmail.com

\section{References}

Butler, Joseph. 1726. Fifteen Sermons Preached at the Rolls Chapel. London: Knapton.

Carnap, Rudolf. 1947. Meaning and Necessity. Chicago: University of Chicago Press.

Chalmers, David J. 2002. On sense and intension. Philosophical Perspectives 16: $135-82$.

Chalmers, David J. 2004. The foundations of two-dimensional semantics. In Two-Dimensional Semantics: Foundations and Applications, edited by M. GarciaCarpintero and M. Macia. Oxford: Oxford University Press.

Church, Alonzo. 1951. A formulation of the logic of sense and denotation. In Structure, Method, and Meaning, edited by P. Henle, H. M. Kallen and S. K. Langer. New York: Liberal Arts Press.

Dejnozka, Jan. 1981. Frege on identity. International Studies in Philosophy 13(1): 31-41.

Dummett, Michael. 1981. Frege: Philosophy of Language, $2^{\text {nd }}$ edition. Cambridge, MA: Harvard University Press.

${ }^{16}$ Thanks to Adrian Heathcote and N. J. J. Smith for encouraging responses to an early version of this paper. Thanks also to the participants at the Australasian Association for Logic Conference 2010 at UNSW, especially Wylie Breckenridge, M. J. Cresswell, David Ripley and Mark Jago. Finally, special thanks to an anonymous referee for detailed comments which led to many improvements. 
Fine, Kit. 2007. Semantic Relationism. Malden, MA: Blackwell.

Frege, Gottlob. 1893. On sense and reference. In Translations from the Philosophical Writings of Gottlob Frege, edited by P. Geach and M. Black. Translated by M. Black. Oxford: Blackwell, 1952.

Frege, Gottlob. 1879. Begriffsschrift. A formula language of pure thought modelled on that of arithmetic. In The Frege Reader, edited and translated by M. Beaney. Oxford: Blackwell, 1997.

Kneale, William and Martha. 1984. The Development of Logic. Oxford: Oxford University Press.

Kripke, Saul A. 1979. A puzzle about belief. In Meaning and Use, edited by A. Margalit. Dordrecht: Reidel.

Morris, Thomas V. 1984. Understanding Identity Statements. Aberdeen: Aberdeen University Press.

Newman, Andrew. 1992. (Untitled) review of Understanding Identity Statements by Thomas V. Morris. Noûs 26(2): 275-277.

Noonan, Harold W. 1986. (Untitled) review of Understanding Identity Statements by Thomas V. Morris. Philosophical Quarterly 36(144): 457-459.

Noonan, Harold W. and Curtis, Ben. 2014. Identity. In The Stanford Encyclopedia of Philosophy (Summer 2014 Edition), edited by Edward N. Zalta. URL = $<$ http://plato.stanford.edu/archives/sum2014/entries/identity/>.

Quine, W.V.O. 1960. Word and Object. Cambridge, MA: MIT Press.

Recanati, François. 2012. Mental Files. Oxford: Oxford University Press.

Russell, Bertrand. 1903. Principles of Mathematics. Cambridge: Cambridge University Press.

Salmon, Nathan U. 1986. Frege's Puzzle. Atascadero, CA: Ridgeview.

Salmon, Nathan U. 1989. How to become a Millian heir. Noûs 23(2): 211-220.

Salmon, Nathan U. 1991. How not to become a Millian heir. Philosophical Studies 62 (2): 165-177.

Soames, Scott. 1987. Substitutivity. In On Being and Saying: Essays in Honor of Richard Cartwright, edited by J. Thomson. Cambridge, MA: MIT Press.

Soames, Scott. 1989. Direct reference and propositional attitudes. In Themes from Kaplan, edited by J. Almog, J. Perry and H. Wettstein. Oxford: Oxford University Press.

Soames, Scott. 1998. The modal argument: wide scope and rigidified descriptions. Noûs 32(1): 1-22.

Soames, Scott. 2002. Beyond Rigidity: The Unfinished Semantic Agenda of Naming and Necessity. New York, NY: Oxford University Press.

Soames, Scott. 2014. The Analytic Tradition in Philosophy, Volume 1: The Founding Giants. Princeton: Princeton University Press.

Strawson, P. F. 1974. Subject and Predicate in Logic and Grammar. London: Methuen.

Thau, Mike and Caplan, Ben. 2001. What's puzzling Gottlob Frege? Canadian Journal of Philosophy 31(2): 159-200.

Weiner, Joan. 1999. Frege. Oxford: Oxford University Press.

Wertheimer, Roger. 1998. Identity: logic, ontology and epistemology. Philosophy 
73(284): 179-193.

White, Roger. 1978. Wittgenstein on identity. Proceedings of the Aristotelian Society New Series 78: 157-74.

Wiggins, David. 1965. Identity statements. In Analytic Philosophy, $2^{\text {nd }}$ edition. edited by R. J. Butler. Oxford: Basil Blackwell.

Wittgenstein, Ludwig. 1953. Philosophical Investigations. Translated by G. E. M. Anscombe. Oxford: Blackwell, 1953. 